\title{
Contribuições do Google Sala de Aula para o Ensino Híbrido
}

\author{
Edson Pedro Schiehl ${ }^{1}$, Isabela Gasparini ${ }^{1,2}$ \\ Departamento de Ciência da Computação - PPGECMT ${ }^{1}$ e PPGCA ${ }^{2}$ \\ Universidade do Estado de Santa Catarina (UDESC) - Joinville, SC - Brasil \\ edschiehl@gmail.com, isabela.gasparini@udesc.br
}

Resumo. Este artigo apresenta o conceito de ensino híbrido e seus diferentes modelos. Posteriormente faz um levantamento sobre as potencialidades do Google Sala de Aula e a utilização de suas ferramentas para o auxílio no processo de ensino-aprendizagem. Como resultado desta pesquisa é apresentada uma proposta de ensino pelo modelo de rotação por estações utilizando as tecnologias e ferramentas existentes. Espera-se que este trabalho estimule outras iniciativas pedagógicas com o uso de ferramentas tecnológicas disponíveis e gratuitas

Palavras-chave: Ensino Híbrido, Google Sala de Aula, Ensino e Aprendizagem, Rotação por Estações.

\section{Contributions of Google Classroom for Blended Learning}

\begin{abstract}
This paper presents the concept of blended learning and its different models. Subsequently it makes a survey about Google's Classroom potential and the use of it tools to aid in the teaching-learning process. As a result of this research is presented a proposal for teaching the rotation model for stations using existing technologies and tools. It is hoped that this work will encourage other educational initiatives with the use of available and free technological tools.

Keywords: Blended Learning, Google Classroom, Teaching and Learning, Rotation.
\end{abstract}

\section{INTRODUÇÃO}

Os espaços educacionais, vitrines de muitos estudos, possibilita aos pesquisadores um contexto complexo as inovações que promovam a eficácia no ensino e no aprendizado dos nativos digitais. Fato de possível constatação, pelos inúmeros trabalhos que apresentam e relatam as aplicações de ferramentas tecnológicas educacionais. (FUNDAÇÃO SANTILLANA, 2016). Moran (2013) identifica uma busca constante de transformar o universo educacional em ambientes motivadores e significativos ao aprendizado, acrescentando ao estudante a necessidade de ser: pesquisador, crítico e tomador de decisão pautado nos conhecimentos científicos.

Segundo Mendes e Lemes (2014), os pesquisadores ainda veem uma grande lacuna entre a realidade do estudante em sala de aula versus as propostas educacionais tecnológicas. Essa lacuna não corresponde somente aos recursos de hardwares ou softwares, os quais muitas escolas tiveram a oportunidade de receber pelos seus governantes (municipais, estaduais ou da união), mas sim, de verificar se esses recursos tecnológicos podem resolver as dificuldades (de estudantes, professores, gestões, etc.) e possibilitar uma melhora no processo de ensino-aprendizagem. Entende-se então que, não somente é necessária a tecnologia, mas como utilizá-la dentro da sala de aula. Assim, Faria 
(2004 s.p.) define que a aplicação inteligente da tecnologia educacional "é aquela que sugere mudanças na abordagem pedagógica", onde dinamizam a colaboração entre estudantes para construção do seu conhecimento.

Desta forma, existem diversos pontos relevantes para dimensionar um trabalho que reúna o processo de ensino-aprendizagem nas escolas por meio da tecnologia. Estudos mais recentes desconstroem os estereótipos da educação tradicional e reconstroem no mesmo meio uma mistura personalizada do ensino e do aprendizado utilizando as tecnologias. (BACICH, TANZI NETO, TREVISANI, 2015). Essa mistura denominada de ensino híbrido (do inglês blended learning) dinamiza cenários diferenciados para que os estudantes desenvolvam, com melhor aproveitamento dos conteúdos, as suas capacidades.

Cada instituição de ensino analisa com os seus profissionais o qual cenário ou modelo de ensino híbrido se adaptada às possibilidades estruturais e funcionais desta. Com isso, esse estudo apresenta um modelo que se adapta as escolas públicas e que desenvolvem o ensino tradicional em sala de aula. O modelo de ensino híbrido denominado rotação por estações possui aspectos de rupturas flexíveis ao modo de trabalho e não afeta a estrutura física existente. No entanto, o estudante necessita de um momento online para desenvolver suas pesquisas. Assim, a proposta de usar o Google Sala de Aula como plataforma é também apresentada, pela gratuidade e ubiquidade aos envolvidos no ensino e no aprendizado. Este trabalho está estruturado como segue: na seção dois o ensino híbrido e seus modelos são apresentados; na seção três o Google Sala de Aula é descrito; na seção quatro uma proposta de ensino pelo modelo de rotação por estações é explorada e na seção cinco são apresentadas as considerações finais.

\section{UMA MISTURA CHAMADA ENSINO HÍBRIDO}

O termo híbrido vem do "misturar", "mesclar", algo 'heterogêneo', que envolva duas ou mais situações/objetos. Na educação, Moran (2015) descreve haver combinações de elementos misturados. São exemplos desses elementos: o tempo, o espaço, os métodos, as atividades e as pessoas que estão em diversos momentos interligadas ou relacionadas. Com essas inúmeras combinações na educação, o ensino híbrido destaca a interação do ser humano com as tecnologias. Assim, essa mistura não necessariamente precisa acontecer entre quatro paredes, ela pode ser adaptada a qualquer ambiente. Isso é possível, graças à ubiquidade tecnológica, ou seja, encontra-se e adapta-se nos diversos ambientes, das mais diversas formas e necessidades.

$\mathrm{Na}$ escola, principalmente no ensino fundamental e médio, ainda se tem o reconhecimento de um ambiente físico, tradicionalmente estruturado por salas de aula, onde acontece a formação dos estudantes. Para esse modelo, o ensino híbrido "está emergindo como uma inovação sustentada em relação à sala tradicional" (CHRISTENSEN, HORN, STAKER, 2013 s.p.). Deve-se entender que o ensino híbrido não tem o propósito de substituir ou extinguir o ensino tradicional, mas o de reunir em um ambiente o melhor de ambos.

No ensino tradicional estão presentes vários fatores que proporcionam o aprendizado do estudante, tais como o professor em sala, colegas com mesmos objetivos e lugares para se concentrarem. Ao relacionar essas características ao ensino híbrido, compartilha-se esse ambiente físico com o mundo virtual, que pode proporcionar a construção do ser crítico, envolvendo o estudante em múltiplas atividades com e sem tecnologias, colaborando para que todos nesse ambiente aprendam. 
Claro que cada instituição educacional determina seu rumo podendo escolher e se adaptar às inovações. Para as escolas que se permitem inovar, existem dois modos: um progressivo chamado de sustentado e outro mais radical definido como disruptível.

Nas escolas que desenvolvem o processo sustentado, muitos aspectos do modelo tradicional são mantidos. Assim, o formato da sala de aula, o currículo e os profissionais adaptam as situações para o melhor envolvimento e desenvolvimento do estudante, agregando atividades diversificadas, tecnologias e modelos mais flexíveis com a estrutura e as condições da escola. (MORAN, 2015b). O outro tipo de escola inovadora é mais disruptiva com o tradicional e Moran (2015b) destaca que essas determinam mudanças significativas, tanto na estrutura física quanto na pedagógica.

Cabe ressaltar que não se predende impor um modelo pronto para que as escolas desempenhem suas atividades. Mas, que elas possam conforme suas condições, personalizar modelos existentes para seus trabalhos, usando as inovações como apoio ao processo de ensino e aprendizagem para essa geração de nativos digitais.

Na próxima seção são apresentados alguns modelos de ensino híbrido observados por Staker e Horn (2012), nos estudos do K-12 (termo utilizado para descrever: (K) - jardim de infância ao (12) $3^{\circ}$ ano de ensino médio nos Estados Unidos).

\subsection{Alguns Modelos de Ensino Híbrido}

Para descrever como modelo de ensino híbrido, Christensen, Horn e Stake (2013 s.p.) definem que é preciso reconhecer como "um programa de educação formal no qual um estudante aprende, pelo menos em parte, por meio do ensino on-line, com algum elemento de controle do estudante sobre o tempo, o lugar, o modo e o ritmo do estudo", e parte em ambiente escolar. Assim dentre os mais de cem modelos pesquisados por Christensen, Horn e Stake (2013), três são destacados como sustentados (escolas tradicionais) e quatro disruptivos (ensino on-line), representados na Figura 1.

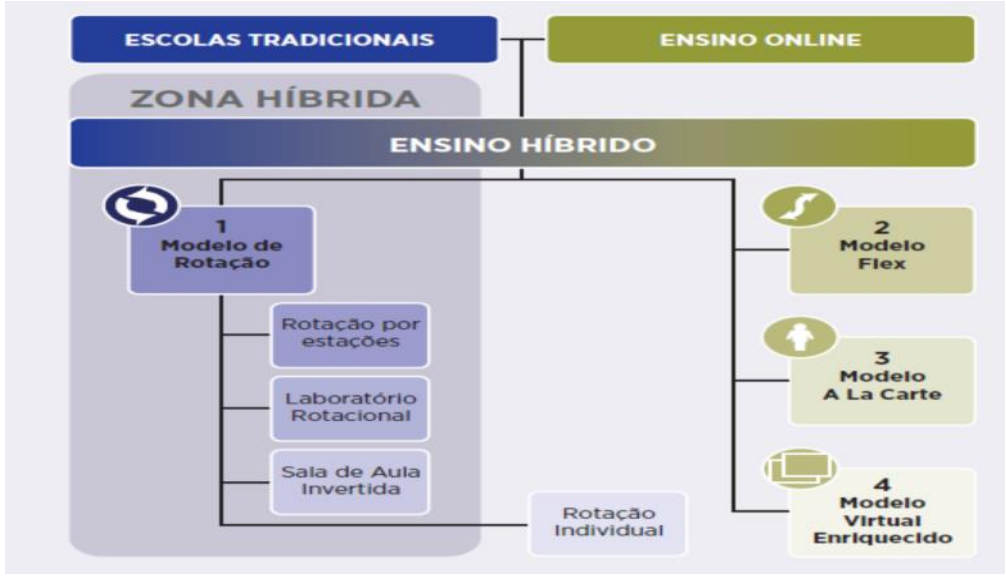

Figura 1 - Modelos de ensino híbrido Fonte: Christensen, Horn e Stake (2013)

\subsubsection{Modelos Sustentados}

Os modelos sustentados do ensino híbrido podem ser desenvolvidos com mais tranquilidade, pois, permitem uma inserção gradativa nos ambientes educacionais, sem gerar grandes rupturas no modelo tradicional, mas com a visão de melhorias no ensino e no aprendizado. 
Dos modelos existentes, foram selecionados: rotação por estações, sala de aula invertida e laboratório rotacional. (BACICH, TANZI NETO, TREVISANI, 2015).

- Rotação por estações: em sala de aula o professor designa três ou mais agrupamentos chamados de estações. Nessa, os estudantes produzem suas atividades organizadas pelo professor em tempos determinados. Cada estação tem uma atividade e pelo menos uma delas é destinada à pesquisa utilizando a internet.

- Sala invertida: seu objetivo é estimular os estudantes a fazerem pesquisas, orientadas pelo professor, em suas casas. Posteriormente, por meio de projetos ou de debates se discute o assunto pesquisado em sala de aula.

- Laboratório rotacional: tem formato parecido com o modelo rotação por estações, no entanto a pesquisa on-line é feita na sala informatizada, o que requer deslocamento dos estudantes e um professor para cada ambiente.

Nos modelos apresentados, além de não criarem grandes rupturas no ensino tradicional, buscam combinar a motivação para aprendizagem nas dimensões: extrínseca (nota, recompensa) e intrínseca (não depende de nota). A importância da dimensão extrínseca está relacionada à criação de rotinas, hábitos e procedimentos, principalmente em iniciantes. Já a dimensão intrínseca é trabalhada para que o estudante perceba que conhecimento é mais importante que atribuição de nota. No entanto, o desafio das escolas é desenvolver a capacidade dos estudantes para agregarem todo o conhecimento de forma contextualizada, integradora e que dê sentido as coisas, sejam quais forem as opções pelas dimensões (MORAN, 2015).

\subsubsection{Modelos Disruptivos}

Os Modelos organizados com estímulos a grande parte do tempo on-line, tem uma visão bastante radical ao cenário do ensino fundamental e médio no Brasil, mas que podem enriquecer os modelos sustentados. Por isso, foram selecionados os modelos: flex, à la carte e virtual enriquecido. (BACICH, TANZI NETO, TREVISANI, 2015).

- Rotação individual: o estudante tem uma lista de atividade que deve ser cumprida em várias estações organizadas na escola e fora dela. Esse plano individualizado requer atenção especial do professor de sala e demais funcionários em outras estações, como por exemplo, os responsáveis pela biblioteca e pela sala informatizada.

- Modelo flex: cada estudante tem a sua lista personalizada de atividades, em grande parte on-line, conforme suas competências e habilidades. O professor fica à disposição para auxiliar em momentos que o estudante achar necessário.

- À la carte: o professor define os objetivos a serem estudados e dá suporte quando necessário. No entanto, é o estudante que se responsabiliza em organizar os estudos que pode ser totalmente on-line.

- Virtual enriquecido: neste modelo os estudantes devem se apresentar ao menos uma vez por semana na escola. Assim, dividem o seu tempo com aprendizagem on-line e presencial.

Apesar desses diversos modelos apresentados, cada escola que pensa em desenvolver um modelo de ensino híbrido pode personaliza-los conforme suas possibilidades, seja esta necessidade com poucos recursos ou totalmente conectada às novas tecnologias. A força motriz é a ideia de quebrar paradigmas e mobilizar todos os 
participantes da educação. No entanto, o destaque fica por conta do professor, que precisa ter habilidade nos aspectos intelectual, afetivo e gerencial. (BACICH, TANZI NETO, TREVISANI, 2015).

\subsection{A Escolha de um Modelo}

Em um contexto geral, Moran (2015) coloca que a educação híbrida requer modelos pedagógicos mais inovadores. Essa busca recorre às análises que cada instituição deva fazer e depois tomar sua decisão. Há fatores que limitam muitas escolas a adotar modelos mais arrojados estão relacionados à necessidade de mudanças físicas (reconstruir ambientes) e pedagógicas (mudanças de currículos e formas de ensino e aprendizagem). Ao dimensionar esses limitantes, possivelmente ainda existirão outros obstáculos a serem vencidos, especialmente para as escolas públicas. Desta forma, a inserção de modelos sustentados é o primeiro passo para o ensino híbrido ser implantado. No entanto, mesmo os modelos sustentados, geram a necessidade de pequenas adaptações. Cada escola precisa observar o que é importante reestruturar antes de iniciar uma personalização dos modelos existentes.

Um exemplo real de escola nessa fase de adaptação é o Colégio Estadual Frederico Guilherme Giese do Paraná, que buscou parcerias e recursos junto à comunidade, ajustando a distribuição de internet wi-fi para toda a escola. Todos os professores e estudantes (mais de 500 por período) têm acesso à internet, nos horários de aula ou intervalos. Para não sobrecarregar a rede com os muitos usuários acessando ao mesmo tempo, foram instalados os UniFis. Esses aparelhos trabalham regulando a quantidade de acessos entre os vários pontos da escola.

Com a estrutura de conexão solucionada, o próximo passo foi implantar uma plataforma que auxiliasse o professor com os conteúdos ministrados. Já que um modelo de ensino híbrido necessita destinar parte do tempo a pesquisas on-line, seja por computadores ou celulares. Com isso a busca por uma plataforma que auxiliasse na organização das disciplinas foi discutida, e pelo levantamento realizado, verificou-se a possibilidade de cadastrar a escola no Google Sala de Aula. Os principais fatores que apoiaram essa escolha foram: à gratuidade da plataforma para instituições públicas e a grande variedade de ferramentas adaptáveis à escola. Na próxima seção, serão tratados os processos e as funcionalidades do Google Sala de Aula adotadas na escola e em outras instituições de ensino.

\section{GOOGLE SALA DE AULA}

Nos últimos anos a Google vem lançado e melhorado ferramentas de suporte tecnológico nas mais diversas áreas. No campo da educação, o destaque está no Google Sala de Aula. Alguns estados, como Paraná e Santa Catarina, já iniciaram trabalhos pilotos com essa ferramenta, segundo as Secretarias de Educação. Mas até o momento, são poucas as escolas que estão implantando os recursos do Google Sala de Aula. Porém, mesmo sem o suporte das Secretarias de Educação, as escolas públicas que não participam desses programas governamentais podem ter a iniciativa de conduzir seu processo de implantação, acessando: G Suite for education. Foi exatamente assim que o Colégio Estadual Frederico Guilherme Giese no Estado do Paraná e recentemente a Escola Estadual Prefeito Carlos Zipperer Sobrinho do Estado de Santa Catarina fizeram.

Então, o que é esse Google Sala de Aula? Segundo Witt (2015), “G Suite for Education oferece um conjunto de ferramentas de comunicação e produtividade destinadas 
a promover a colaboração e criatividade.". O autor ainda diz que, o "desenvolvimento das habilidades de: comunicação, colaboração, pensamento crítico e criatividade", são potencializadas ao utilizar as tecnologias do século 21. Assim, todos os envolvidos no processo educacional desenvolvem a confiança com a tecnologia e, possibilitam uma aprendizagem mais significativa e híbrida no contexto de sala de aula. (WITT, 2015).

O Google Sala de Aula é uma sala virtual, onde o professor organiza as turmas e direciona os trabalhos, usando ou não as demais ferramentas do Google Apps. O professor acompanha o estudante no desenvolvimento das atividades e, se necessário, atribui comentários e notas nas produções realizadas. A cada nova atividade inserida, os estudantes recebem uma mensagem no e-mail, independente se o estudante compareceu nas aulas presenciais e há a possibilidade do estudante participar ativamente das atividades complementares ou de pesquisa. Além disso, o professor pode convidar os responsáveis dos estudantes, cadastrando seus e-mails, para acompanhar o desenvolvimento de seus filhos nas atividades, agendas e avisos pertinentes - um vínculo que aproxima família e escola.

O acesso no Google Sala de Aula é restrito aos estudantes e funcionários cadastrados pela escola. Este cadastro é vinculado a um domínio relacionado à instituição, promovendo assim mais autenticidade e organização dos assuntos relacionados à escola.

O Google Sala de Aula define um link direto com o Google Drive. Quando o professor cria uma nova sala, automaticamente no Drive é criada uma pasta para esta e todas as novas inserções serão armazenadas lá. Na interface do Google Sala de Aula, as atividades já concluídas podem ser excluídas. No entanto, o professor poderá revê-la a qualquer momento pelo ícone de controle do fluxo.

O professor pode disponibilizar materiais sobre os conteúdos que preparou para sua aula no espaço "Sobre". Esse espaço busca no Drive os conteúdos definidos em documentos, formulários, vídeos, apresentações, entre outros. Esses documentos ficam à disposição do estudante, para ver, rever e desenvolver suas atividades. Logo após as atividades concluídas, o professor pode lançar a nota relacionada a esse trabalho. Essa nota pode ser visualizada pelo estudante, como também baixada em tabela de controle do professor.

Como o estudante recebe todas as informações que são registradas no Google Sala de Aula, minimiza possíveis esquecimentos ou falhas. Também facilita a observância dos prazos e alertas de atividades a serem cumpridas. Para os estudantes com dúvidas em certa atividade extraclasse, eles podem se conectar com o professor de forma síncrona (Hangout) ou assíncrona (Gmail), o que possibilita um estreitamento na comunicação de professor e estudante, não permitindo que as dúvidas se tornem possibilidades de desmotivação.

Além do que foi mencionado sobre o Google Sala de Aula, Witt (2015) reuniu algumas ferramentas que auxiliam o trabalho do professor, mostrada na Tabela 1. Essa tabela foi adaptada demonstrando algumas outras ferramentas que dinamizam o ensino e o aprendizado.

Tabela 1 - Algumas ferramentas no Google Sala de Aula (Adaptado de Witt (2015)).

\begin{tabular}{|l|l|l|}
\hline Ferramenta & Google Apps & Características Chaves \\
\hline Universal & $\begin{array}{l}\text { Características } \\
\text { Universais dos } \\
\text { aplicativos. }\end{array}$ & $\begin{array}{l}\text { Os arquivos são salvos automaticamente e se cria um histórico de } \\
\text { revisão completo com um carimbo de data e hora de todas as revisões } \\
\text { de todos os arquivos e todos os compartilháveis. Permite múltiplos } \\
\text { usuários colaborarem em um único documento com ambiente de } \\
\text { processamento baseado em nuvem, capacidade de comentário web, }\end{array}$ \\
\hline
\end{tabular}




\begin{tabular}{|c|c|c|}
\hline & & portanto, sempre acessar a versão mais recente do aplicativo. \\
\hline $\begin{array}{l}\text { Sala de aula - } \\
\text { dentro e fora da } \\
\text { escola }\end{array}$ & $\begin{array}{l}\text { Classroom ou } \\
\text { Sala de Aula. }\end{array}$ & $\begin{array}{l}\text { - Sistema de gestão de sala de aula para professores; } \\
\text { - Gerencia múltiplas classes e níveis; } \\
\text { - Posta mensagens anúncios (perguntas, avisos e tarefas) para uma ou } \\
\text { mais classes; } \\
\text { - Gerencia tarefas e compartilhamento de arquivos (formulários, } \\
\text { documentos, vídeos, link, etc.); } \\
\text { - Sala de aula tem um código de acesso protegido; }\end{array}$ \\
\hline $\begin{array}{l}\text { Apps } \\
\text { Calendário }\end{array}$ & Agenda & $\begin{array}{l}\text {-Conectado a uma Conta do Google acessível através de qualquer } \\
\text { navegador web e dispositivo móvel habilitado, organizando eventos e } \\
\text { atividades. }\end{array}$ \\
\hline $\begin{array}{l}\text { Armazenamento } \\
\text { de arquivos na } \\
\text { nuvem }\end{array}$ & Drive & $\begin{array}{l}\text { Sistema de armazenamento baseado em nuvem. Permite o } \\
\text { compartilhamento de arquivos com outra conta do Google ou contas } \\
\text { fora do ambiente Google permite download de arquivos para um } \\
\text { disco rígido para ser acessado off-line. }\end{array}$ \\
\hline Textos & Documentos & $\begin{array}{l}\text { Tem a capacidade de expandir os recursos disponíveis e } \\
\text { funcionalidade com uma extensa lista de add-ons. Compor textos. }\end{array}$ \\
\hline $\begin{array}{l}\text { Planilha } \\
\text { eletrônica }\end{array}$ & Planilhas & $\begin{array}{l}\text { Funcionalidade básica de uma planilha tem a capacidade de expandir } \\
\text { os recursos disponíveis com uma extensa lista de add-ons. }\end{array}$ \\
\hline $\begin{array}{l}\text { Apresentação } \\
\text { em slides }\end{array}$ & Apresentações & $\begin{array}{l}\text { Funcionalidade básica de um software de apresentação tem a } \\
\text { capacidade de expandir os recursos disponíveis e funcionalidade com } \\
\text { uma extensa lista de add-ons. }\end{array}$ \\
\hline $\begin{array}{l}\text { Formulário de } \\
\text { pesquisa e } \\
\text { coleta de dados. }\end{array}$ & Formulários & $\begin{array}{l}\text { Envio do formulário diretamente ligado a uma planilha, para facilitar } \\
\text { a captura de dados simples e análise de grandes volumes de dados. } \\
\text { Ferramenta de grande utilidade na formulação de atividades } \\
\text { diagnósticas. }\end{array}$ \\
\hline Desenho & Desenhos & Ferramentas básica de desenhos geométricos e livres. \\
\hline Mapas & My Maps & $\begin{array}{l}\text { Permite destacar trajetórias, localização e medidas em mapas. } \\
\text { Permite ainda adicionar camadas. }\end{array}$ \\
\hline Criação de Sites & Google Sites & $\begin{array}{l}\text { Interface similar a outros Google Apps permite a criação colaborativa } \\
\text { de um site pode inserir imagens, vídeos, bem como Google } \\
\text { Documentos, Planilhas e Apresentações diretamente de seus sites do } \\
\text { Google Drive pode ser privado ou público com os professores que } \\
\text { controlam o acesso para estudantes de criação de simples ferramentas } \\
\text { e modelos para início rápido }\end{array}$ \\
\hline Mídia Social & Google+ & $\begin{array}{l}\text { Permite criar grupos para compartilhar documentos e colaborar } \\
\text { através de discussões on-line em um ambiente de mídia social. }\end{array}$ \\
\hline
\end{tabular}

Existe uma série de outras ferramentas e aplicativos que podem fazer parte da sala de aula, as quais o professor pode adaptar conforme sua necessidade.

Portanto, uma plataforma que possibilita a interação, organização e a orientação ao ritmo de estudo do estudante, como a do Google Sala de Aula é importante para personalizar um modelo de ensino híbrido. Por exemplo, o trabalho de Dicicco (2016) trata do uso do Google Sala de Aula e confirma a melhora na motivação e no aprendizado dos estudantes. No entanto, Dicicco (2016) acrescenta que são necessários mais estudos, principalmente na adequação de metodologias com o uso da plataforma.

Observando a contribuição de Dicicco (2016), este trabalho analisou a utilização do modelo de rotação por estações por se mostrar menos disruptível ao processo de internalização pelos estudantes, bem como ao de se adaptar facilmente nas estruturas da escola. A próxima seção apresenta a proposta do ensino híbrido pelo modelo de rotação por estações, utilizando o Google Sala de Aula. 


\section{UMA PROPOSTA DE ENSINO PELO MODELO DE ROTAÇÃo POR ESTAÇÕES}

O uso do Google Sala de Aula como ferramenta de apoio tecnológico aos estudantes foi o primeiro passo para organizar uma sala no modelo de rotação por estações. Pois, segundo BACICH, TANZI NETO e TREVISANI (2015), para esse modelo é necessário ao menos um espaço com interação on-line. Além do espaço com aparato tecnológico pode ser criado outros espaços para que o estudante desenvolva seus estudos. A Figura 2 permite uma demonstração do rodízio que os estudantes fazem pelas estações estabelecidas nesse modelo.

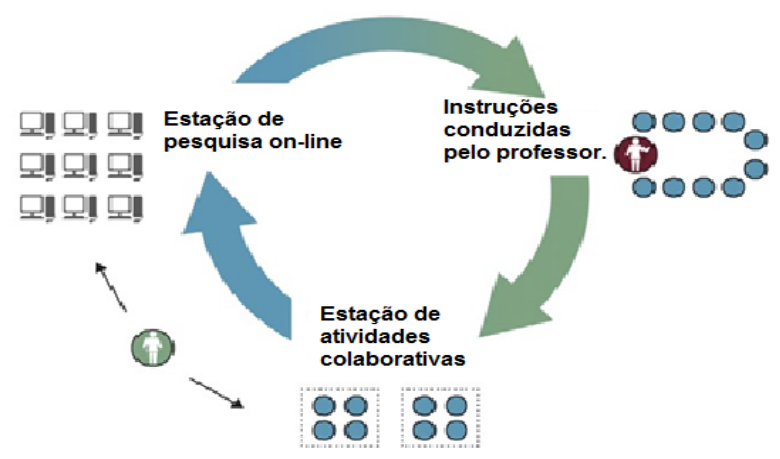

Figura 2 - Modelo de Rotação por Estações

Fonte: Staker e Horn (2012). Adaptada pelos autores desse artigo.

O próximo passo a ser adotado no Colégio Frederico Guilherme Giese é desenvolver o ensino híbrido integrando todas as disciplinas e professores de cada ano escolar. Esse processo foi iniciado pelas aulas de matemática, devido ao engajamento de alguns professores com o Google Sala de Aula e a flexibilidade para mudanças.

Para tal, o modelo de rotação apresentado na Figura 2 foi organizado em três grupos: azul, verde e amarelo. Essa divisão foi pensada para facilitar a montagem da sala nos grupos. No primeiro grupo, há dez carteiras no canto da sala denominado de estaçãa azul on-line. Nesse local ocorrerem às pesquisas e atividades com os celulares e tablets dos estudantes. Outro espaço foi preparado, com mais dez carteira agrupadas, denominado de estação verde colaborativa, local de colaboração em pares com troca de conhecimentos e ajuda mutua entre os estudantes. Por fim, um espaço com carteiras separadas para atividades e estudos individualizados, denominado de estação amarela atenção. Nesse espaço cada estudante desenvolve suas atividades de pesquisa por leituras e exercícios direcionados por nível de complexidade.

Em cada estação o professor designa atividades sobre determinado assunto, organizando-os por níveis de complexidade. Na estação azul, os estudantes têm acesso ao seu Google Sala de Aula, o qual apresenta os vídeos relacionados com o tema, links de atividades criadas nos Apps do Google ou Quizzes como o da Khan Academy. Nesta estação os estudantes com maior dificuldade podem rever os vídeos, bem como refazer as atividades. No entanto, para os estudantes com maior facilidade, esses poderão avançar a níveis mais complexos do assunto ou então, auxiliar seus colegas.

$\mathrm{Na}$ estação amarela os estudantes recebem uma lista de atividades (que podem ser auxiliadas pelo livro didático). Neste espaço, o professor é mais presente para orientar e facilitar a organização e o progresso nos estudos. Já na estação verde a colaboração dos 
colegas possibilita o reforço nas atividades, pelas discussões de possíveis dúvidas, equalização no entendimento sobre o assunto e evolução do aprendizado.

A organização desses agrupamentos está sendo realizada de forma organizada e detalhada para que a cada aula os estudantes saibam seus procedimentos. O layout da sala dependerá de cada estrutura física e a quantidade de estudantes, no caso da escola citada, há uma regularidade de trinta estudantes. Por fim, cada estudante terá um tempo para passar em cada estação, que será determinado por um alarme registrado no celular do professor. Atualmente, na escola em questão, o tempo determinado é de quinze minutos em cada estação e três minutos para organização das carteiras, totalizando os quarenta e oito minutos de aula.

Esta nova abordagem está sendo inicializada nas aulas de matemática, e espera-se que em um futuro próximo, se estenda para toda a escola. Apesar da turma ainda não ter finalizado o ano letivo, já é possível perceber como resultado qualitativo, um maior engajamento dos estudantes durante as aulas, além do aumento colaborativo entre eles.

Outro aspecto importante é o planejamento do professor. Ele precisa estar ciente de que pode existir um desconforto inicial na mudança de sua rotina e seu planejamento requer atenção a cada uma das três áreas. Todas as atividades devem ser pensadas em diversos níveis de resolução (fácil, moderado e elaborado) para que o estudante desenvolva as suas capacidades. Talvez seja o trabalho mais difícil de ser pensado e estruturado, mas ao concluir essa parte o professor vai adaptando seu trabalho conforme a turma se desenvolve. Por fim, para que os trabalhos fluam com mais praticidade em sala, deve-se escolher estudantes-chave, que possuam facilidade na disciplina, para auxiliarem outros estudantes.

\section{CONSIDERAÇÕES FINAIS}

Este trabalho fez um levantamento do conceito de ensino híbrido, apresentando alguns modelos existentes. Além disso, analisou a ferramenta Google Sala de Aula como suporte para o ensino híbrido e ao final apresenta uma proposta que está sendo implementada em uma escola de ensino público fundamental e médio. Neste primeiro momento o ensino híbrido está sendo realizado nas aulas de matemática do $2^{\circ}$ ano do ensino médio, e trinta estudantes estão participando, pela abordagem Modelo de Rotação por Estações e por meio das ferramentas do Google Apps, especialmente o Google Sala de Aula.

Como resultado até o momento, percebeu-se que no modelo tradicional, onde os estudantes se organizavam em forma de fileiras, o professor exercia pouco contato com muitos deles, principalmente nos fundos da sala. Além disso, esse modelo tradicional colabora com o desinteresse nos conteúdos tratados em sala, dado a falta de proximidade do professor (MORAN, 2015). Com isso, a nova disposição organizada no modelo de rotação por estações possibilita um maior contato do professor e estudante, como também a colaboração entre estudante com estudante. $O$ foco da aula está na aprendizagem do estudante que se percebe como parte da turma quando é atendido em suas dificuldades, seja pelo professor ou pelos próprios colegas que tem mais facilidade. Fato que corroborou com um aumento no engajamento dos estudantes nas aulas de matemática.

\section{REFERENCIAS}

ANDRADE, M. C. F. SOUZA, P. R. Modelos de Rotação por Ensino Híbrido: estações de trabalho e sala de aula invertida. In: Anais da E-Tech: Tecnologias para Competitividade Industrial, Florianópolis, v.9, n.1, 2016. Disponível em: 
$<$ http://revista.ctai.senai.br/index.php/edicao01/article/view/773>. Acesso em 22 out. 2016.

BACICH, L.; TANZI NETO, A.; TREVISANI, F. M. Ensino híbrido: personalização e tecnologia na educação. Porto Alegre: Penso, 2015.

CHRISTENSEN, C.; HORN, M. B.; STAKER, H. Ensino Híbrido: uma Inovação Disruptiva? Uma introdução à teoria dos híbridos. [2013]. Disponível em: $<$ https://s3.amazonaws.com/porvir/wp-content/uploads/2014/08/PT_Is-K-12-blendedlearning-disruptive-Final.pdf $>$. Acesso em: 19 out. 2016.

DICICCO, K. M. The effects of Google Classroom on teaching social studies for students with learning disabilities. Disponível em: $<$ http://rdw.rowan.edu/etd/1583/>. Acesso 20 out. 2016.

FARIA, E. T. O Professor E As Novas Tecnologias. In: ENRICONE, Délcia (Org.). Ser Professor. 4 ed. Porto Alegre: EDIPUCRS, 2004 (p. 57-72). Disponível em: $<$ http://aprendentes.pbworks.com/f/prof_e_a_tecnol_5[1].pdf $>$. Acesso em: 22 out. 2016.

FUNDAÇÃO SANTILLANA. Tecnologias para a transformação da educação: experiências de sucesso e expectativas. Disponível em: $<$ http://fundacaosantillana.org.br/seminario-tecnologia/pdf/tecnologias-para-atransformacao-da-educacao.pdf $>$ Acesso em: 20 out. 2016.

HORN, M. B.; STAKER H. Blended: usando a inovação disruptiva para aprimorar a educação. Tradução: MONTEIRO, M. C. G. Porto Alegre, RS: ed. Penso, 2015.

MENDES, S. M. C.; LEME, M. E. G. A Mediação Pedagógica: formação docente para a educação inclusiva frente ás novas tecnologias. In: Anais do I Encontro Internacional Tecnologia, Comunicação e Ciência Cognitiva, São Paulo, 2014. Disponível em: $<$ http://www.revista.teccog.net/index.php/revista_tecccog/article/view/29/43>. Acesso em: 22 out. 2016.

MORAN, José. Educação Híbrida: um conceito-chave para a educação, hoje. In: BACICH, L.; TANZI NETO, A.; TREVISANI, F. M. (Org.). Ensino híbrido: personalização e tecnologia na educação. Porto Alegre: Penso, 2015.

- Mudando a Educação com Metodologias Ativas. In: Coleção Mídias Contemporâneas. Convergências Midiáticas, Educação e Cidadania: aproximações jovens. Vol. II] Carlos Alberto de Souza e Ofelia Elisa Torres Morales (orgs.). PG: Foca Foto-PROEX/UEPG, 2015. Disponível em: <http://www2.eca.usp.br/moran/wpcontent/uploads/2013/12/mudando_moran.pdf>. Acesso em 20 out. 2016.

WITT, D. Accelerate Learning with Google Apps for Education. [2015]. Disponível em: $<$ https://danwittwcdsbca.wordpress.com/2015/08/16/accelerate-learning-with-googleapps-for-education/>. Acesso em: 23 out. 2016.

STAKER H.; HORN, M. B. Classifying K-12 Blended Learning. In: Innosight Institute, 2012. Disponível em: <http://www.christenseninstitute.org/wpcontent/uploads/2013/04/Classifying-K-12-blended-learning.pdf $>$. Acesso em 20 out. 2016. 